\title{
Ill Health, Death and Loneliness: Mankind's Companions
}

\author{
Ami Rokach ${ }^{1,2,3,{ }^{*}}$ and Ami Sha'ked ${ }^{3}$ \\ ${ }^{I}$ York University, Canada \\ ${ }^{2}$ Walden University, MN, USA \\ ${ }^{3}$ Center for Academic Studies, Israel
}

\begin{abstract}
In this paper we review the concept of loneliness, and research that relates it to illness and death, two conditions that we all will undergo at some point in our life, and which are replete with loneliness, a sense of isolation, and a deep yearning not only for health and life, but for a meaningful connection with loved ones and carers.
\end{abstract}

Keywords: Loneliness, hospitalization, illness, death, palliative care.

"Loneliness, which can involve excruciating physical as well as mental suffering, is an ancient nemesis. In fact, the first thing that the biblical God named as not good was loneliness. Loneliness is implicated in numerous somatic, psychosomatic, and psychiatric diseases [1]. It is a mundane yet arcane human affliction that is often hazardous to health and hostile to happiness" [2]. This paper is a review of the experience of loneliness as it affects us when we are not doing well, such as when we are ill, or on our deathbed.

Sullivan [3] observed that modern medical science has been focused, and we may say even obsessed with death. Death provided medicine a clear 'enemy'. Consequently, medical research has focused on conquering specifically the diseases that cause death. That gave medicine social prestige and a gigantic budget. Physicians are often seen as possessing super natural abilities, as they are the front line fighters with serious diseases and death. Only lately are we becoming more aware of the importance of considering who the patient, as a person is. That is the goal of primary care medicine. They, therefore, focus on care of the patient, and only then focus on the disease which that person has. The time of illness and hospitalization, let alone when we are close to end our journey on earth, are stressful, often frightening, and (almost always) the times when we are most dependent on the support of those whom we love and our circle of friends and family. When we do not get the support and empathic care that we crave, loneliness results.

Loneliness is a universal experience shared by all humans. Being a uniquely subjective experience, it is caused by the individual's personality, environmental and social changes, and one's history [4]. That history includes, of course, the kind of illnesses and the cultural context of those diseases that one may have been afflicted with.

*Address correspondence to this author at the Center for Academic Studies, Israel; E-mail: arokach@yorku.ca

\section{ILLNESS \& LONELINESS}

Illness is a major stressor on one's life [5]. Various symptoms, such as pain, fatigue, and in more severe cases, immobility and even loss of bodily functions and control put the body into a state of continuous stress [6]. After being hospitalized as a result of illness, individuals experience a wide range of short term as well as long term consequences and effects [7, 8]. In general, it is not only the physical suffering and distress that puts body into a state of continuous stress, but also factors that negatively affect the patient's psychological state. Factors such as perceived threat to ones' life, the uncontrollable and unpredictable nature of one's condition often put hospitalized individuals in a state of apprehension and hopelessness, which can have a considerable effect on their thoughts, emotions, and subsequent behaviours [8-10].

Examining the effects of loneliness on the body and the immune system, Cohen [11] observed that life events including separation, loss, and feelings of hopelessness, which are associated with the experience of loneliness, affect the endocrine system through abnormal secretion levels from the pituitary and adrenal glands. That may adversely affect the immune system and therefore, decrease the body's ability to fight illness and/or result in an increased vulnerability to develop cancer. Deterioration in health through this process is most probable in persons with already compromised immune functioning, especially persons with the Acquired Immune Deficiency Syndrome (AIDS), an immunosuppressive disease [12]. Research found that high loneliness scores are also correlated with significant lower levels of natural killer cell activity, which are the lymphoid immune cells that play a role in cancer protection and appears to have antitumor and antiviral capabilities [13].

The nature of people's interconnections with others and their perceptions of those relationships, have been attracting research in an attempt to explain alternatives in physical and mental health. Research has repeatedly demonstrated that 
those with social support had stronger immune systems $[14,15]$. However, those with fewer social ties had increased susceptibility to illnesses [16]. In general, when close relationships are discordant, they are often associated with immune deregulation [12]. It has been suggested that people who have well established social support, seem to be better able, than other people, to cope with stress and chronic pain. Moreover, social isolation rivalled other well-established risk factors - such as cigarette smoking, high blood pressure, obesity and sedentary life style - as a risk of poor health. It was also found that people with higher rates of social support have better health and lower rates of mortality. In that study it was observed that participants that had the fewest social ties, were two to four times more likely to die than those who were well supported $[17,18]$.

\section{LONELINESS ASSOCIATED WITH MEDICAL DIAGNOSIS}

Many patients are familiar with the feelings of anxiety and loneliness following the diagnosis of a disease or illness, or with the experience associated with awaiting a diagnosis or procedure [see, for example, 19]. It was that patients undergoing diagnostic processes are prone to feelings of uncertainty and anxiety [20].

Several studies have examined women's experience with abnormal mammograms or women who were suspected of having breast cancer. Breast cancer is one of the most common and deadly cancers amongst women. Women, it was found and intuitively apparent, experience anxiety from the time a breast lump is discovered, or an abnormal mammogram report is received, and reaches its peak when the patient is preparing for a breast biopsy [19]. Thorne, Harris, Hislop, and Vestrup [21] interviewed a number of women awaiting a diagnosis after an abnormal mammogram was detected, in order to better understand their experience. The time period until a diagnosis was reached was described as a time of being "in limbo". These women described serious disruptions to their daily existence, insomnia, panic attacks, inability to concentrate at work, inability to plan, and preoccupation with fears. They considered themselves 'suspended' from their participation in the course of normal living. In addition, and that may have added to their loneliness, some of the women kept their abnormal mammogram results a secret from loved ones. Similar research with men awaiting a prostate cancer diagnosis has been performed. Prostate cancer is one of the most common malignancies affecting men. Men who are undergoing screening for prostate cancer report high anxiety levels [22]. Other studies examined the experience of patients awaiting medical procedures, more specifically radiologic procedures. Compared to many other types of medical procedures and surgeries, image guided diagnostic procedures are often cutting edge and less invasive. It stands to reason that they will thus arouse less anxiety and alienation. But patients awaiting these procedures report anxiety, fears of the unknown, possibility of further interventions, destruction of body image, disruption of life plans, loss of control and disability, as these medical professionals harbour uncertainty and stress [23, 24]. Flory and Lang [25] conducted a study comparing the distress levels in women awaiting large core breast biopsy for diagnosis of suspicious lesions with distress levels of women undergoing invasive, potentially risky treatment of diagnosed malignancies of the liver and those undergoing invasive, potentially risky treatment of diagnosed benign uterine tumors. All of the groups in the study experienced abnormally high levels of perceived stress and depressed mood, but only women awaiting breast biopsy experienced abnormally high anxiety levels. The authors concluded that the invasiveness of the procedure has less influence on patients' distress, than feeling of alienation has on their levels of unease and distress. Those procedures, that may be followed by a diagnosis of an illness, many times a serious one, no doubt cause the patients to feel alone in their waiting for an answer, in deciding how their future will unfold, and in their fight to remain alive and healthy.

Illness may be a crisis for the ill person as well as for her family. Chronic illness may cause a redefinition of one's identity, the relationship between married partners and between them and their children is often affected [26, 27]. Families of young children who are ill suffer even more, as in addition to the heartache in seeing their child ill, they must also continue their relationship and manage the host of problems related to caring for a sick child such as the financial demands of the treatment, absence from work, and of the future, should the ill have a terminal condition [28].

Illness is a major stressor on one's life [5]. Various symptoms put the body into a state of continuous stress which may include pain, fatigue, and in more severe cases, immobility and even loss of bodily functions and control [6]. Being hospitalized, individuals experience a wide range of consequences and effects [7,29]. In general, it is not only the physical suffering and distress that puts the body into a state of continuous stress, but also factors that negatively affect the patient's psychological state [8]. These include perceived threat to one's life, the uncontrollable and unpredictable nature of one's condition, and the state of apprehension and hopelessness, which can have a considerable affect on the thoughts, emotions, and behaviours of the patient $[9,10,30]$.

\section{THE DYING}

As Rando [31] so poignantly indicated, death "is not romantic. It is not graceful. It is not beautiful. In fact, death stinks - literally and figuratively! It is clammy too. It can sounds bad, and it often is ugly" (p. 272). Consequently, people with terminal illnesses may be spending the more advanced stages of their illness in a hospice. Many dying patients receive palliative care when there is little that can be done to cure them, and the goal is then to help them die with as little discomfort as possible, and with dignity. Palliative care may be provided in a hospice or at home, with the goal of achieving the best possible quality of life for the dying patients and for their families, and to provide them with dignified treatment and lower their distress for their final days [32]. Van Bommel [33] eloquently observed that palliative care provides "physical, emotional, spiritual and informational support to help improve the quality of a person's remaining life, and recognizes the patient and family as the principal decision makers" (p.22).

Palliative care views dying as a normal process, rather than as a medical failure. It neither hastens nor postpones death, while aiming to make the patient as pain free, and 
comfortable as possible. As Cushing [32] so aptly observed "A physician is obligated to consider more than the diseased organ, more even than the whole man - he must view the man in his world" (p.29). Palliative care, thus, takes a holistic view and integrates the psychological, physical, social and spiritual aspects of a patient's care. It offers a support system that enables and encourages patients to live as actively as possible until death, and helps the family cope [during the patient's illness] with the bereavement; anticipatory and post mortem [32, 33]. And lastly, palliative care offers a support system to the patient and to his (often) distressed family. Twycross [34] maintained that the locus of control in hospice care must be redirected to the dying patient. He goes on to point out that when health restoration is no longer possible, care and not cure, should be the focus.

One of the most excruciating elements of death is the leaving of all that the patient owned, had and known behind. Separating from friends and family is not only one of the most heart-wrenching aspects of dying - but also a precursor of loneliness and aloneness. Loneliness has been documented to be central for both the patient and his or her caregivers [see 35,36].

\section{THE PATIENT}

People who are ill and dying may pose particular demands for their carers. The patient may be difficult because of his or her pathology, which may affect her behaviour and/or personality, such as brain tumor/s, cerebrovascular disease, or concurrent illnesses (e.g. Hypothyroidism). Pharmacological agents such as over sedation or Tardive Dyskinesia may exacerbate the situation. Psychological factors and psychiatric disorders may result in a patient who is very demanding and difficult to handle; these include anger, mistrust, fear, or shame which are directed towards the carers, or depression and paranoia which even in healthy people often disrupt theirs and the lives of those close to them. The patients' symptoms are another contributor to a patient being difficult to care for. Those may include gross disfigurement, malodor, poor response to symptom management and somatization [34].

\section{NEEDS OF THE PATIENT}

Rokach and Rokach [37] presented a multidimensional model of patients' needs, including the following:

Physical/medical needs - these include pain and symptom management, the need to have a warm and caring environment, and the patient's need to have a sense of control in regard to their treatment.

Social needs - completing unfinished business, the needs to love and to be loved, to forgive or be forgiven, and to sustain trusting and intimate relationships.

Emotional/Psychological needs - those include maintaining a sense of control, affirmation of one's existence, searching for meaning, and finding the courage to "let go" and bring closure to one's life.
Spiritual/ religious needs - having a sense of hope and inner peace, being able to participate in cultural observances and in prayers.

Connor [38] observed that people respond differently to their impending death. Most often their behaviour is characterized by ambivalence- "fearful avoidance and the desire for release" (p. 46). Results of the present study thus indicate that in the midst of that ambivalence - which most probably is experienced by the patient and the caregiver Self-alienation may be the dimension of loneliness that they most acutely experience. And indeed, a form of distancing and numbing may be needed in facing the end of life and the impending separation from loved ones.

To conclude, loneliness is part of being human and consequently, we experience it, particularly acutely at times of stress, illness or during the process of dying. It was not the focus of this chapter to include coping strategies with the pain of loneliness, but research that I [AR] and other researchers carried out indicated that it is, indeed, possible to alleviate (at least to some degree) the pain of loneliness and suffering of alienation.

\section{CONFLICT OF INTEREST}

The authors confirm that this article content has no conflict of interest.

\section{ACKNOWLEDGEMENTS}

Declared none.

\section{REFERENCES}

[1] Mcgraw JG. The first of all evils. in: wawrytko sa, ed. the problem of evil. an intercultural exploration. Atlanta, GA: Editions Rodopi Bv 2000; pp. 145-58.

[2] Martens WHJ, Palermo GB. Loneliness and associated violent antisocial behavior: analysis of the case reports of jeffrey dahmer and dennis nilsen. Int J Offender Ther Comp Criminol 2005; 49(3): 298-307.

[3] Sullivan M. The new subjective medicine: Taking the patient's point of view on health care and health. Soc Sci Med 2003; 56 : 1595-604.

[4] Rokach A, Brock H. The causes of loneliness. Psychol J Hum Behav 1996; 33: 1-11.

[5] Sellick S, Edwardson AD. Screening new cancer patients for psychological distress using the hospital anxiety and depression scale. Psycho-Oncology 2007; 16(6): 534-42.

[6] Rowe MA. The impact of internal and external resources on functional outcome in chronic illness. Res Nurs Health 1996; 19(6): 485-97.

[7] Pressman MR, Meyer T, Peterson DD, Greenspon LW, Figueroa WG. Effects of hospitalization, surgery, and anesthesia on sleep and biological rhythms. Washington, DC: American Psychological Association 1997.

[8] Rattray M, Johnston JA, Wildsmith W. Predictors of emotional outcomes of intensive care. Anesthesia 2005; 60: 1085-92.

[9] Seeman M, Seeman TE. Health behavior and personal autonomy: a longitudinal study of the sense of control in illness. J Health Soc Behav 1983; 24 (2): 144-60.

[10] Mishel M. Perceived uncertainty and stress in Illness. Res Nurs Health 1984; 7(3): 163-71.

[11] Cohen IS. Psychosomatic death: voodoo death in modern perspective. Integr Psychiatr. 1985; 16: 46-51.

[12] Kiecolt-Glaser JK, McGuire L, Robles TF, Glaser R. Psychoneuroimmunology: psychological influences on immune function and health. J Consult Clin Psychol 2002; 70(3): 537-47. 
[13] Kennedy S, Kiecolt-Glaser JK, Glaser R. Immunological consequences of acute and chronic stressors: mediating role of interpersonal relationships. Br J Med Psychol 1988; 61: 77-85.

[14] Glaser R, Kiecolt-Glaser JK, Bonneau RH, Malarky W, Kennedy $\mathrm{S}$, Hughes J. Stress-induced modulation of the immune response to recombinant hepatitis B vaccine. Psychosom Med 1992; 54: 22-9.

[15] Hagerty BM, Williams RA, Coyne JC, Early MR. Sense of belonging and indicators of social and psychological functioning. Arch Psychiatric Nurs 1996; 10(4): 235-44.

[16] Cohen S, Doyle WJ, Skoner DP, Rabin BS, Gwaltney JM.Jr. Social ties and susceptibility to the common cold. JAMA 1997; 277: 1940-4.

[17] Berkman LF, Syme SL. Social networks, host resistance and morality: A nine-year follow-up study of Alameda County residents. Am J Epidemiol 1979; 109: 186-204.

[18] Brannon L, Feist J. Health psychology: An introduction to behaviour and health. Toronto, Canada: Thomson Wadsworth 2004.

[19] Chappy S. Women's experience with breast biopsy. AORN J 2004; 80(5): 885-901.

[20] Liao M, Chen M, Chen S, Chen P. Uncertainty and anxiety during the diagnostic period for Women with suspected breast cancer. Cancer Nurs 2008; 31(4): 274-83.

[21] Thorne S, Harris S, Hislop G, Vestrup J. The experience of waiting for diagnosis after an abnormal mammogram. Breast J 1999; 5(1): 42-51.

[22] Dale W, Bilir P, Han M, Meltzer D. The role of anxiety in prostate carcinoma. Cancer 2005; 104(3): 467-78.

[23] Johnston LD, O'Malley PM, Bachman JG. National survey results on drug use from the Monitoring the Future study, 1975-1993 (NIH Publication No. 94-3810). Washington, DC: U.S. Government Printing Office 1994.

[24] Viegas L, Turrini R, da Silva Bastos Cerullo J. An analysis of nursing diagnoses for patients undergoing procedures in a Brazilian interventional radiology suite. AORN J 2010; 91(5): 544-47.

[25] Flory N, Lang E. Distress in the radiology waiting room. Radiology 2011; 260: 166-73.
[26] Christ GH, Siegel K, Freund B, et al. Impact of parental terminal cancer on latency-age children. Am J Orthopsychiatry 1993; 63: 417-25.

[27] Palmer SE, Canzona L, Wai L. Helping families respond effectively to chronic illness: Home dialysis as a case example. In Moos RH, Ed. Coping with physical illness 2: New perspectives. NY: Plenum Press 1984; pp. 283-94.

[28] Schilling LS, Grey M, Knafl, K. A review of measures of selfmanagement of type 1 diabetes by youth and their parents. Diabetes Educ 2002; 28: 796-808.

[29] Incalzi RA, Gema A, Capparella O, Muzzolon R. Effects of hospitalization on affective status of elderly patients. Int Psychogeriatr 1991; 3(1): 67-74.

[30] Raps CS, Peterson C, Jonas M, Seligman MEP. Patient behavior in hospitals: Helplessness, reactance, or both? J Pers Soc Psychol 1982; 42: 1036-41.

[31] Rando T. Grief, dying and death. Champaign, Ill: Research Press 1984.

[32] Faull C, Woof R. Palliative Care: An Oxford Core Text. New York: Oxford University Press 2002.

[33] Van Bommel H. Dying for Care: Hospice Care or Euthenesia. Toronto: NC Press 1992.

[34] Twycross R. Introducing palliative care, $4^{\text {th }}$ ed. UK: Radcliffe Medical Press 2003.

[35] Doka KJ. When illness is prolonged: implications for grief. In: Doka KJ, Ed. Living with grief when illness is prolonged. Washington, D C: Hospice Foundation of America 1997; pp. 5-16.

[36] Rokach A, Matalon R, Safarov A, Bercovitch M. The dying, those who care for them, and how they cope with loneliness. Am J Hosp Palliat Med 2007; 24(5): 399-407.

[37] Rokach A, Rokach B. The dying and the living: Caring for the patient and for the professional who treats him/her. A keynote address delivered at the eighth annual Conference of Palliative Medicine, Tzfat, Israel, May 192005.

[38] Connor SR. Hospice: Practice, pitfalls, and promise. Washington, DC: Taylor \& Francis 1998.

(C) Rokach and Sha'ked; Licensee Bentham Open.

This is an open access article licensed under the terms of the Creative Commons Attribution Non-Commercial License (http://creativecommons.org/licenses/by-nc/3.0/) which permits unrestricted, non-commercial use, distribution and reproduction in any medium, provided the work is properly cited. 